\title{
Una dosis de vacuna anti-varicela no confiere protección duradera
}

\author{
A single dose of anti-varicella vaccine does not confer long term protection
}

\section{Objetivo}

Valorar la perdurabilidad del efecto protector de la vacuna antivaricela en niños.

\section{Diseño}

Cohorte retrospectiva* con datos provenientes de 300 sitios de vigilancia epidemiológica (guarderías, escuelas, consultorios médicos, instituciones de salud).

\section{Lugar y participantes}

Valle de Antellope, California, EEUU (1995-2004).

\section{Medición de resultados principales}

Sobre cada caso de varicela reportado (rash máculo-pápulovesicular sin otra causa aparente) y estimándose una tasa de reporte de $70 \%$, se recabaron datos epidemiológicos, demográficos y clínicos, determinándose los ocurridos en vacunados ("rash" compatible con varicela aparecido más allá de los 42 días de la vacunación) y los moderado-severos (más de 50 lesiones al diagnóstico).

\section{Resultados}

Durante diez años se reportaron 11.356 casos, 1080 (9,5\%) en vacunados. Los vacunados hacía más de cinco años tuvieron mayor incidencia de varicela moderada-severa que los vacunados en los cinco años previos al estudio (RR 2,6; IC95\% 1,2$2,8)$. La tasa anual en vacunados (ajustada por edad, año de vacunación y comienzo de la enfermedad) aumentó desde 1,6 a 58,2 pacientes/año* entre el primero y el quinto año post vacunación. Desde la implementación de la vacunación en 1995 el pico de casos se trasladó a edades mayores (seis a nueve
Chaves S et al. N Engl J Med 2007;356:1121-9. años en los vacunados y nueve a 12 en los no vacunados) y la proporción de enfermedad moderada-severa se incrementó a mayor edad de contagio en vacunados y en no vacunados.

Tabla 1: factores asociados a varicela severa en vacunados.

\begin{tabular}{l|c|c|c}
\hline \multicolumn{2}{c|}{ En anios } & No/total (\%) & $\mathbf{P}^{*}$ \\
\multirow{2}{*}{$\begin{array}{l}\text { Edad al comienzo de la } \\
\text { enfermedad }\end{array}$} & Uno a siete & $166 / 771(22)$ & $<0,001$ \\
\cline { 2 - 4 } & Ocho a 12 & $104 / 281(37)$ & \\
\cline { 2 - 4 } & Mayores de 13 & $12 / 27(44)$ & \\
\hline \multirow{2}{*}{ Período en riesgo } & $1995-1998$ & $28 / 156(18)$ & $<0,001$ \\
\cline { 2 - 4 } & $1999-2000$ & $71 / 327(22)$ & \\
\cline { 2 - 4 } & $2001-2004$ & $183 / 596(31)$ & \\
\hline \multirow{2}{*}{ Edad a la vacunación } & Uno a dos & $154 / 667(23)$ & 0,004 \\
\cline { 2 - 4 } & Tres a cinco & $88 / 304(29)$ & \\
\cline { 2 - 4 } & Mayores de seis & $40 / 108(37)$ & \\
\hline \multirow{2}{*}{$\begin{array}{l}\text { Tiempo desde la } \\
\text { vacunación }\end{array}$} & Menos de cinco años & $172 / 744(23)$ & $<0,001$ \\
\cline { 2 - 4 } & Más de cinco años & $110 / 335(33)$ & \\
\hline
\end{tabular}

*Los valores de $\mathrm{p}$ surgen de comparar la primera con la última estimación de cada categoría.

\section{Conclusiones de los autores}

La protección de una única dosis de varicela se desvanece con el tiempo. Sería necesario considerar la administración de una dosis de refuerzo.

Palabras clave: Vacuna contra la varicela-inmunidad-inmunización de refuerzo. Key words: varicella vaccine, immunity, booster immunization

Fuente de Financiamiento: Centro de control de Enfermedades de Estados Unidos (CDC).

\section{Comentario}

En EEUU la vacuna contra la varicela forma parte del calendario oficial desde 1995 y se recomienda en una dosis para los menores de 12 años y en dos dosis para los mayores. En Argentina no forma parte del calendario nacional pero se encuentra en el mercado para administración personalizada a un costo de aproximadamente u\$s50 indicándose en una dosis única a partir del año de vida.

Los vacunados tienen una tasa de seroconversión de hasta $95 \%$. Un estudio argentino observacional y retrospectivo sobre 97 niños vacunados y posteriormente expuestos al virus de la varicela arrojó una tasa de protección de $82,5 \%$ para casos leves y de $95,2 \%$ para moderados ${ }^{1}$. El estudio de Chaves y col. es bienvenido ya que existían dudas sobre la duración de la inmunidad con una única dosis, con el riesgo de que los vacunados queden expuestos al virus salvaje en etapas más avan- zadas de la vida, donde la enfermedad severa y complicada es más probables. Además, la vacunación masiva reduciría la circulación del virus en la comunidad, necesaria para reactivar la inmunidad celular/humoral de los vacunados, lo que afectaría aún más su inmunogenicidad. Esta información se refleja en la reciente recomendación del CDC de incorporar una segunda dosis entre los cuatro y los seis años de edad ${ }^{2}$.

\section{Conclusiones del comentador}

Parece prudente esperar recomendaciones nacionales y datos de costo-efectividad antes de llevar a la práctica esta nueva dosificación.

Gabriel Villalón [ Servicio de Medicina Familiar y Comunitaria. Hospital Italiano de Buenos Aires. ]

Recibido el 20/4/07 y aceptado el 28/05/07

Villalón G. Una dosis de vacuna anti-varicela no confiere protección duradera en niños. Evid. actual. práct. ambul; 10(3): 72, May-Jun 2007. Comentado de: Chaves $\mathbf{S}$ et al Loss of vaccine-induced immunity to varicella over time. N Engl J Med 2007;356:1121-9. PMID: 17360990

Referencias

1. Marcó del Pont J. Eymann A y col. Efectividad de la vacuna contra la varicela: Estudio descriptivo de niños vacunados en un hospital universitario. Arch. Argent. Pediatr.

1. Marco del Pont J. Eymann A y col. Efectividad de la vacur

2. ACIP Provisional Recommendations for Prevention of Varicella. Disponible en:

http://0-www.cdc.gov.mill1.sjlibrary.org/nip/vaccine/varicella/varicella_acip_recs_prov_june_2006.pdf 